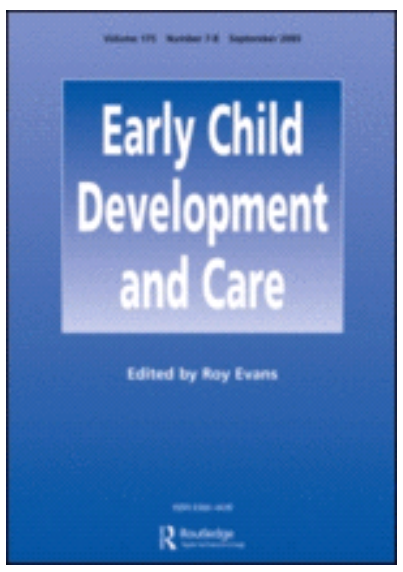

Symbolic gesturing: Creating opportunities for emotional connections between practitioners and infants in day care.

\begin{tabular}{|r|l|}
\hline Journal: & Early Child Development and Care \\
\hline Manuscript ID & GECD-2019-0287.R1 \\
\hline Manuscript Type: & Original Article \\
\hline Keywords: & symbolic gesturing, infants, daycare, practitioner, biographical research \\
\hline \multicolumn{2}{|l}{} \\
\hline
\end{tabular}

SCHOLARONE ${ }^{m}$

Manuscripts 


\title{
Symbolic gesturing: Creating opportunities for emotional connections between practitioners and infants in day care.
}

\begin{abstract}
This article reports on how symbolic gesturing was applied in a nursery setting. Forms of signing systems have been well documented as contributing to communication, predominately used alongside speech when there is a different mother tongue or a physical impairment (Felix, 2018; Goodwyn and Acredolo, 1993) Symbolic Gesturing (SG), is an emerging area to support pre-verbal infants in communicating more effectively. In this article SG was evaluated as way of reflecting and developing practitioner's emotional responses and initiations with the infants in their care. The narratives of three practitioners using SG were gathered over several months and revealed how SG created further opportunities for reflection regarding the emotional relationships with infants they cared for. SG was considered a valuable approach to enhancing the emotional interactional connections with infants, resulting in closer, more attuned relationships.
\end{abstract}

Key words: symbolic gesturing; infants; day care; practitioner; biographical research

\section{Introduction}

A growing body of research recognises the value placed on practitioner's knowledge and understanding around infants' emotions and emotional regulation. Less research however has been focused on the practical integration from the practitioner's perspective, in how emotional wellbeing could be successfully achieved. This article (informed by a larger project on emotional relationships) focuses on whether symbolic gesturing (SG) is viewed by practitioners as an appropriate and beneficial approach to enhance their emotional connections with the infants' in their care. Olson and Masur (2013) concluded mothers responded more frequently and used more verbal responses when infants' communicative attempts involved gestures. Parents' positive responses have shown to increase infants' attempts at vocalization and gestures (Miller and Lossia, 2013). Therefore, this study extends recent studies, beyond the parent relationship to explore whether SG could facilitate more purposeful and intimate practitioner-child interactions within an Early Childhood and Education and Care setting (ECEC).

The questions asked were:

- What is the impact of SG as an approach to enhance emotional connections in an Early Childhood and Education and Care setting (ECEC)?

- Does SG provide a purposeful approach to enable practitioners to reflect on their own emotional connections during everyday interactions with the infants in their care? 


\section{Research on the Emotional Relationship in Early Childhood and Education and Care context (ECEC):}

The curriculum offered within day care in England is termed the Early Years Foundation Stage (Department for Education, 2014, 2017). The curriculum fosters an approach which refers to the infant needing an individualised intimate relationship, and providing consistent care (Department for Education, 2014, 2017; Dryden, Forbes and Pound, 2005; Elfer, 2006; Elfer et al, 2005; Elfer, et al, 2012). The importance of bonding and attachment has therefore been given increasing emphasis in the current English early years' sector, in growing recognition of the emphasis on emotional relationships in European and US policy frameworks (OECD, 2006; Clarke-Stewart and Allhusen, 2005). In English policy frameworks the practitioner's role has been described as a key person with responsibility for a small group of children, enabling close bonds to be achieved (DfE, 2014; Degotardi and Pearson, 2010; Wilcock, 2007). The emphasis being opportunities for infants to form attachments with one or two key practitioners who can be regularly available to the infant in a sensitive consistent and responsive way (Brooks-Gunne, Sidle-Fulligini and Berlin, 2003; Dowling, 2014; Dryden et al, 2005). Being regularly left with professional carers beyond the home in ECEC settings can potentially result in the infant being anxious and insecure if their emotional needs are met inconsistently or misunderstood. Developing bonds and promoting attachments with key practitioners in ECEC settings has therefore been the catalyst in providing responsive and personalised relationships (Belsky et al, 2007; Elfer, 2008; Lee, 2006; Datler, Datler and Funder, 2010). As well as having a commitment to good quality care, the emotional investment of practitioner's role in looking after infants within a setting is also currently a legal requirement within the EYFS curriculum (DfE, 2012, 2017). The role involves opportunities to support and enable all children to feel safe, express their feelings, be aware of who they are and what they can accomplish. This is achieved through care, attentiveness and interaction (Drugli and Undheim 2011; Hopkins, 1988; Barnes, 1995). A relationship of comfort and knowing, using a range of approaches to bridge the communicative and emotional responsiveness gap, helps reduce these anxieties often faced by infants in transitioning to and regularly attending ECEC settings (Dowling, 2014; Ebbeck, 2009; Mooney, 2010). Interaction by listening to infants enables practitioners to create meaningful activities and aids connections with them (Abbott and Moylett, 2003; Manning-Morton and Thorp, 2006). Practitioners are encouraged to engage young infants to respond to, or mimic adults through approaches such as interactive gesturing. Symbolic gesturing could extend this by gaining an understanding of infant needs and requests, and therefore be valuable in creating and enhancing meaningful relationships (Capone and McGregor,2002; Daniels, 2004; Nelson, et al, 2012). By tuning in and promoting SG alongside speech, mutual interactions between infant and carer can be enhanced, through physical communicative messages culminating in an emotional communicative dance (Trevarthen 2009). The carer can adapt their interactive behaviour to the rhythms of their infant and encourage the infant to 


\section{Theoretical Framework: Symbolic Gesturing: meanings and interpretations}

The literature on symbolic gesturing (SG), as a specific type of a signing system that focused on the affective domain of infants' and carers' and carer perspectives using SG were included in the search criteria. Studies that evaluated the impact of infant and carer communication were also reviewed. The methodological approaches of the studies were assessed, and predominately studies with qualitative, alongside mixed method approaches were included in the review.

Two types of infant gestures are commonly identified: deictic gestures and symbolic or representational gestures (Capirici et al, 1996). Deictic gestures such a pointing and reaching are among the first gestures observed (Locke, 2007). SG are naturally occurring gestures framed in a way so the consistently manipulated gestures of the hand represent something meaningful both to the infant and adult using them. They carry meaning in their form to symbolise and express what is being conveyed and can stand alone in much the same way as words (Goodwyn et al, 2000; Capone and McGregor, 2004; Messinger and Fogel, 1998; Pizer et al, 2007). In verbal and SG communication, the development of reciprocal responses from the caregivers to the infants, interactions and emotional interactional behaviour of infants have been shown to be enhanced (Vallotton, 2009; Capone and McGregor, 2004; Goodwyn et al, 2000). Ochs and Schieffelin (1984) also found that when symbolic gestures were promoted, understanding and naming items improved, thus requesting objects was met with understanding, and from an infant's perspective the desired outcome met. SG has since developed into an important early communication behaviour capable of predicting and supporting language development (Goodwyn, Acredolo, and Brown, 2000; Rowe and Goldin-Meadow, 2008). It has the capacity to integrate infants into their cultural world of communication by developing socially appropriate behaviour. 
However, the value of SG has been received with caution (Gwyneth, 2008). Howlett, Kirk and Pine (2011) indicated parental stress could be increased when attending signing classes if visible success was not evident. However, the parents attending such classes were perceived to have possible pre-existing levels of stress and therefore any approach could be reported as stressful with some parents. In a smaller scale study Mueller and Sepulveda (2014) noted that the stress levels in nine families attending infant signing workshops did not increase. They concluded infant signing workshops had beneficial results, such as enhanced interactions, communication and increased bonding experiences between parents and their infants. Vallotton $(2009,2012)$ and Kirk et al (2013) also supported the notion that using SG compels the caregiver to become more responsive to the child. Both studies demonstrated that mothers who had experience and knowledge of SG were more responsive to their child's needs than those who were not exposed to SG. Similarly, Zammit and Atkinson (2016) evaluated maternal mind mindedness was evident during SG, with the infant considered a communicative partner rather than helpless. They concluded SG aided parents view of their infants as an autonomous individual, owning their own emotions rather than an extension of their mothers'. Vallotton (2017) extended this and evaluated when SG was delivered by adults sensitively and in response to infants needs the infants responded more frequently. In conclusion, qualitative care-giver sensitivity to infant's interactions using SG was as important and more so, than the quantity of SG used. This suggested SG required a sensitive practitioner who was emotionally invested in the infant, practitioner relationship. In extending this research the current study presented in this article adopted a qualitative, rather than quantitative approach. Practitioners' views were explored to discover the potential of SG to enhance their emotional interactions and therefore improved the relationship with infants in their care (Miller t al, 2005; Glaser and Strauss, 1999, Mueller, Sepulveda, 2014; Vallotton, 2008). This paper has drawn specifically on the voices of the practitioners in a bid to understand how fruitful SG became in making emotional connections with the infants in their care. In doing so it aimed to add to the growing but currently minimal body of work that has investigated the effect on emotional relationships of gesturing, specifically in ECEC contexts in England (Namy, et al 2000; Vallotton, 2015; Vallotton, 2008; Tomasello and Farrar, 1986).

\section{Materials and Methods}

In this case study approach, the focus was upon understanding and illuminating the views of three practitioners using SG during a three-month period about how it enhanced the relationships with the infants they care for (Johnston, et al, 2005). Therefore, the aim of the case study approach was to understand the subjective world of the individual experience and go beyond the observed behaviour in consideration of their perspectives through description and interpretation (Denzin and Lincoln, 2008).

\section{Contextual Journey}


A typical privately-owned day nursery was selected in terms of numbers, parent partnerships and age ranges offered in a local community.

An initial group meeting for all the practitioners was held and they were asked if they would like to take part in the study. This was important because coercion of staff to take part would have affected the outcome. Of those willing to participate in the study the participants were recruited according to three criteria: a) working with infants under two years in the daily setting, b) different positions held within the day care and c) prior experience regarding use of signing systems. The sample was therefore considered a reasonably representative of the practitioner population working in a day nursery. All participants worked full-time and held a national childcare qualification.

Practitioner 1: a senior member of the team with managerial responsibilities

Practitioner 2: a senior practitioner with higher level qualifications

Practitioner 3: a practitioner, qualified to responsibly practice with a small group of children

\section{Interview approach}

Individual interviews were held at the beginning of the three-month period, during the introductory phase of understanding and learning about SG. A further interview for was held at the end of the three months with each practitioner. The interviews were designed to minimise anxiety and create a relaxed atmosphere where practitioners felt able to share their views and understanding of symbolic gesturing (Yin, 2009). The approach was aimed to obtain the voices of the practitioners' experiences as they implemented SG. It was grounded in a desire to illuminate the complexity of the individual lives through analysis of data to provide greater insight into the social, cultural network and lived experience of using SG (Erben, 1998).

\section{Interview Process}

The interviews were intended to give voice to three practitioners who would not ordinarily have their social situations or viewpoints shared with a wider audience (Kvale, 2006). Each practitioner was therefore allocated time to share their journey and experiences of implementing SG over a three-month period. A broad open-ended question regarding their thoughts of symbolic gesturing was posed at the beginning of the interview. The practitioners then led the remainder of the interview reflecting and sharing their thoughts verbally. The interviewer repeated statements and prompted the practitioners' where applicable so as to remain focused on the purpose of the interview. Awareness of the researchers' own position during the interviews was essential in enabling a trusting and collaborative atmosphere to promote the authenticity of practitioners' responses rather than feel exploited and manipulated (Collier and Collier, 1986; Noland, 2006; Kvale, 1996, 2006). In response to reducing the manipulation of the 
dialogue, all interviews were recorded using an audio device and completed verbatim transcripts were given to the practitioners a week post interviews. This member check aimed to the enhance advocacy of the practitioners, validate their own narrative and obtain consensual knowledge (Collier and Collier, 1986).

\section{Limitations and ethical considerations}

A combination of reasons may create a barrier in sharing thoughts (Elfer, 2006). When the practitioner interpreted the use of SG and their emotional journey, they may have focused more on the approach superficially or be uncertain in how to articulate their emotional connectivity with the infants in their care. Factors such as the practitioner's own upbringing or having had complex and challenging conversations with parents may militate against articulating and sharing information about their professional emotional relationships with infants. Trust and time were therefore essential for the research to have any credibility. In seeking permission emphasis was placed on the commitment to better understand the practitioners' perspectives in delivering SG rather than making critical evaluations of their practice. Protocols including the right to withdraw and opt in were adhered to and guidelines were followed using university criteria as part of a doctoral study.

\section{Analysis Process}

A social constructivist theoretical frame was employed whereby the practitioners drew on their social and cultural resources to construct meaning with the infants they cared for (Yin, 2009). Meaning is defined therefore as constructed rather than fixed and it is open to interpretations by the researcher depending on the practitioner's choice of narratives, they shared regarding the implementation of SG.

The data was analysed thematically using the procedures recommended by Braun and Clarke (2006). Thematic analysis involved searching through the data sets of each practitioner's interviews to find repeated patterns in the transcripts. of ideas and common words. The transcripts were then read and reread and subsequently organised into categories and colour coded accordingly. These categories included general thoughts about SG, frequency of using SG, the quality of communication using SG, personal reflections and roles when communicating with infants using SG. Common themes between the categories were sought, for example; using SG as a form of non-verbal communication during music time. Further structured analysis then took the form of comparing themes whilst taking note of high frequency words such as body language, tuning in, and emotions. Moving back and forth through the data sets assisted the process of interpreting and making sense of the practitioners' words, so enabling their ideas and meanings to be derived and subsequently clarified alongside theory (Collier and Collier, 


\section{Results and Discussion}

\section{Making emotional and intersubjective connections using SG}

At the beginning of the SG journey the practitioners described their emotional relationship with the infants they cared for. Practitioner one stated the objectives of the job description were achieved by the infants being comforted, although how they were comforted was not clearly defined:

As primary carer in our setting, evidence of settling the infants in is when the infant looks for comfort and goes to the key person. They seek for comfort and the key persons seem pleased to be with them.

In the initial interview prior to SG being used, practitioner two described her role regarding emotional relationships as a person who is aware of personal needs; making the infants feel valued as individuals in addition to meeting their learning needs:

I feel a key person is somebody who takes care of the children's needs, their complete needs and the holistic needs of that child. It is our role to make them feel secure and to make them feel valued when they come and play with us.

Whilst practitioner three, tended towards the practitioner's duties in terms of children's learning rather than the attachments formed in emotional relationships:

Well the role of the key person in this setting is quite specific and is discussed with members before they start working so there is not any doubt what their role is. They have their own key children; obviously they have a small group of children who they are responsible for ... they are responsible for observing those children for using those observations to plan activities for the children linked to the medium term plan and then evaluate those activities and decide the next step for their own children... their own. They also keep the children learning journeys files.

Within the early years curriculum there is an expectation for that practitioners foster individualised and intimate relationships with key infants they routinely care for (DfE, 2014.2017, Elfer et al 2012). 
However, practitioners three predominately defines her role through the responsibilities within a curriculum frame rather than an emotional lens in caring for infants. This rather cool, bureaucratic and official response highlighted the legislative requirements of a key person's role rather than the expectations of care for the infants in their care. Practitioner three was the most senior of the participants with the highest responsibility in the team, she therefore possibly regarded this response as the answer expected. Towards the end of the initial interview with the same key person, it became evident that some personal qualities were recognised as necessary but not fully defined:

The personal qualities a staff member needs to have are a sense of humour, they need to be kind and caring, they need to care about the children to make them feel secure...they need to be interested in the children's wellbeing

These qualities; humour, kindness and care whilst perhaps not recorded in a job description are aspects culminating in developing a bond and attachment with infants. Increasing emphasis on emotional relationships have formed part of the early years discourse within practice (Braun and Clarke, 2006). However, approaches to develop, understand and articulate these emotionally complex relationships are less evident. Findings show that a shift occurred in the practitioners' emotional reflective thinking when they used SG in their daily practice. Rather than describing their job descriptions and broad expectations of their role, they were able to evaluate and articulate how SG provided a way of reviewing their emotional connections during daily routines. They expressed how SG helped to build their confidence in becoming more expressive with the infants in their care. It also allowed the practitioners to initiate a novel approach with the infants and learn together at a self-directed pace rather than having it imposed on them by senior management. As practitioner two revealed in the post-interview:

The way we learnt how to symbolically gesture was through a dvd, which was actually very musical and expressive. We found watching the dvd with the children was much more useful than sending a girl to go on a training course who would be then too embarrassed to use signs and try to show us. When we did makaton we didn't actually use them in the end, and it was difficult to get other staff to copy them

In practice using SG enabled the practitioner to be less inhibited and natural in their interactions with the infants. Practitioner two considered how the infants felt when being directly spoken and signed to making them feel wanted and cared for, therefore enhancing emotional connections (Pugh and Duffy, 2013). It was something that perhaps hadn't been employed previously and therefore focusing upon the emotional relationship and how the child became more aware of the one-to-one relationship was significant as she continues:

It definitely helped the emotional relationship because of the closeness that has developed during signing and I am becoming much more self-aware, the infants are also being responded to on a much 
more personalised level than before symbolic gesturing...I am even more eager to find out what is inside those wonderful brains!! As a key worker, my relationships with my key children are far more personal. I find I am helping all the children and responding to them all one by one, not just through signing but also through eye contact and facial expressions. I am really observing now! Before with a lot going on it was easier to leave the quiet children alone and interact less with them. They didn't seem to need my attention as much whilst others I felt were still very dependent on me and needy.

Practitioner two reflected on how SG interactions enabled her to respond to infants as individuals rather than providing them with group care. She also noted that her responses were influenced by infants' temperaments, and their emotional demands. In viewing the infants as separate individuals and being aware of their own minds as working independently rather than reacting as a helpless and dependent corresponds with the maternal mind mindedness within the practitioner infant's relationship (Zammitt and Atkinson, 2016).

As a result of symbolic gesturing, the 'quieter' infants' who had previously been left for longer were now getting more individual attention with the practitioners becoming more attentive and sensitive to the infants' needs rather than as a general response to the infants' behaviour (Brooks-Gunn et al, 2003: Dowling, 2014). The moment of 'tuning in' to individual infants can be helpful in unexpected ways, because they often express emotions that they find impossible to deal with by themselves (Smith, Cowie and Blades, 2005; Trevarthen, 2001). In responding to singular moments of an infant trying to selfregulate their own emotions internally the practitioner is able to tune in to an infant withdrawing or less responsive by using verbal and visual cues with SG to support them. This can be particularly true for those infants who would perhaps previously been marginalised by the more demanding and expressive infants (Mooney, 2010). Therefore, as an approach to support their role in tuning in and providing comfort and warmth, SG was considered significant by the three practitioners during the subsequent interviews as a way of being physically and emotional available to the infant.

Tuning in to an individual child was therefore recognised by practitioner one as an important contribution of SG to enable her to react to the infant as an equal partner in the relationship and the relaxed atmosphere of using SG enhanced their interactions:

It was not something the infants could fail at, or be expected to do, and because I and the children were learning it together, it was quite nice and more personal with both having time to develop together. I think it also enhanced the relationship between myself and child $J$ as he is showing more awareness of feelings and his emotions. he faces you when communicating and makes hand gestures for me to come when I am wanted or needed, helping me to meet his needs more quickly and appropriately. He did not do this before and would seem accepting and passive during the day, not really giving much away. Now we seem to flow together more in our interactions. 
The practitioners' responses highlight the emotional communicative dance of attunement with their behaviour adapting to the rhythms of the infant, allowing them to lead the interaction through proto conversations (Trevarthen, 2001). As the term suggests, the patterns of turn taking include mutual attention, changes in movement, smiling and so on. In cognitively developing the emotional relationship meaningful communication was occurring between carer and infant (Meil and Dallos, 2005; Gerdhardt, 2004; Trevarthen, 2009; Vallotton, 2017).

Reflecting on this further, practitioner three drew on the interactional challenges' practitioners faced when being confronted with an infant's feelings and emotions. She touched upon the complexities and tensions of their role:

Any sort of interaction, including generally observing, has to be achieved through one-to-one interactions where the practitioner is able to tune-in to the child. I think symbolic gesturing has real potential here because signing is something tangible that can be carried out as a way of communicating, not just verbally but with your body too. I think it encourages practitioners to think about how they use their hands, but also their facial expressions and bodies. There are things you can always teach to practitioners and demonstrate, but the emotional interaction aspect of care is very difficult to teach and very difficult to model. Sometimes the less experienced staff are so inhibited and concerned they are doing something wrong they hold back, not wanting to make a fool of themselves. I suppose one reason for this could be their own social care from their own environment and the way they were exposed to emotions and interactions as a young infant. Therefore, their own upbringing is undoubtedly influential in how they professionally care for the infants at day care. This is why I think signing and supporting each other is helpful in relaxing and interacting, trying to understand what the infants they care for want and emotionally expressing.

This highlighted how individualised care could be defined, interpreted and acted upon, to some extent by the practitioner's own experiences and upbringing of emotional relationships. This could be a contributing factor to the amount practitioners emotionally invest in the relationship with the infants they care for. Specifically, they may draw upon - particularly at stressful times - their own experiences of comfort, attending to needs in relation to what they have been influenced by (Belsky et al, 2007). If a practitioner's lack of experience or restraint in love and comfort is prevalent, actively observing and listening to changes in behaviour and tuning-in can be superficial or minimal (Taggart, 2011). This can potentially result in the emotional needs of infants being overlooked and, or misinterpreted (Mooney, 2010).

Practitioner three evaluated the way SG has been used as a way for practitioners to approach their role and enhance attachments during interactions: 
If it's used correctly and systematically by enthusiastic key workers it can develop connections and security, being in touch with the infants. It slows the adults down in their approaches and interactions and provides better eye contact with the child. In a busy day care the staff will sometimes talk to each other and talk over the infants' heads, which I know can happen at home too. However, signing helps to get down at the child's level and face the child and actually communicate and engage with them rather than barking out directions or comments and not really listening to them.

Practitioner two also reflected back to the time before she used SG and compared it to the present making her more aware and closer to the infant she cared for, thus reducing the likelihood of stressful situations occurring;

Right from the beginning when we did our first interview, I thought it would maybe help, although I was cautious about speech being affected, used less by myself and the infants. I wanted to make sure I did the two together. Since using signs, I have noticed my emotional relationships with the children I look after has developed. I feel I have communicated my feelings and understood theirs better. It has brought a closeness I had not expected. The older children in the baby room, who are using more $S G$ are tending to show more self-awareness and I am more aware of meeting their needs too. I feel I more confident and expressive of my emotions and read the infants cues better. I would have liked to have done something like this when I trained.

SG is therefore an approach not simply to aid verbal communication but also an opportunity for the practitioner to reflect on their facial expressions, hand and body movements and general behaviours when interacting and emotionally engaging with the infant. As practitioner two noted using SG as part of a multi-faceted way of communicating, recognition of emotional responsiveness from both the infant and her individually and together was therefore an empowering realisation (Hochschild, 2003).It is a form of communication that encourages the practitioner to observe and listen to themselves and the infants in their care, with purpose, thus creating a greater understanding of what the infant is trying to convey and therefore emotionally investing in the relationship (Vallotton, 2010). Whilst there has been reservations and concerns Olson and Masur (2013) found mothers who used SG responded more frequently with signs and verbally, and through these positive attempts in turn encouraged infants to increase attempts at vocalising and signing (Miller and Lossia, 2013).

SG was also thought to be a way to guide the infants through direct communication with them and form a close attachment as illustrated in a response from practitioner two about being a 'mother hen' and guiding the infants. Mother hen is defined as someone who assumes an overtly protective maternal attitude and ambience (Holmes, 2001).

The practitioners are signalling and guiding their body language... It's more mother henning now in the way we work with the infants than we had previously. 
This maternal attitude and overtly protective behaviour forms part of what is considered as creating opportunities for forming attachments. Attachment is not a one-off event but a developmental process, occurring as a function of the developing relationships between babies and young children and their caregivers. Infants develop internalised working models of relationships which change because of experience and, in light of new information they receive, about how people relate and connect to one another, as in the example of the 'mother hen' type approach towards them (Bowlby, 2005; Holmes, 2001).

Similarly, practitioner one recognised how SG had not only helped the infants in developing attachments, but also the practitioners in being able to express emotions and bond within the infants:

It helped me to communicate and let the infants express their emotions to me. Because of this it helps me understand their own emotions more, giving me the confidence as a practitioner to connect more with my key children and treat them as individuals in their own right. I feel I have really got to know them and meet their emotional needs more fully than before.

Zammitt and Atkinson (2016) considered that SG enhanced infant autonomy and promoted awareness of infants growing independent emotions and therefore as a result parents were adjusting their own interactions with them. As indicated by the practitioner's comments above SG has supported bonding and attachment, facilitated emotional relationships to developed and promoted a nurturing relationship that enabled infants to become autonomous individual rather than completely dependent upon the practitioner.

\section{Understanding infants' emotional wellbeing using SG}

Interview responses at the end of the implementation of SG illustrated a shift in how the three practitioners were able to articulate and reflect on their own practice and the complexity of their role. For example, practitioner three referred to the practitioner role as emotional and maternal and that SG had improved their emotional engagement with the infants in their care:

When you are a mother with a young baby on your own you will do all sorts of daft faces, raspberry noises, tickle their tummy. Less experienced practitioners are inhibited to touch the child in that way and therefore using signing that doesn't inhibit them helps in a way to train them to actually want to do the same sort of things you want to do at home with baby where you would be making your own gestures up.

Practitioner three highlighted the parallels between the relationship of parent and infant with that of the practitioner and infant. The parent-infant relationship suggests a sense of instinctual emotional 
responses and initiations at some level with close bonding taking time, effort and attention to develop. Using SG seems to have facilitated a similar bonding process between practitioner and infant (Bowlby, 1997). Having an atmosphere that was stress free when introducing SG in a fun and relaxed way was important in its successful implementation in enhancing bonds between infant and practitioner (Kirk and Pine, 2010; Mueller and Sepulveda, 2014).

When bonding is achieved successfully, richer and more personalised relationships occur, with each being valued for the contribution they make when interacting (Zammit and Atkinson, 2016). Practitioner two recognised these closer personal relationships after the period of implementation, in the post-interview she commented that a more intimate form of recognising achievement was sometimes preferable to a more generalised praise:

It's really being in tune with the individual. Some children appreciate a smile, or a thumbs up a lot more than verbal communication such as 'wow, look, at what such and such has done'.

Celebrating achievement was, therefore, recognised as being approached differently than previously because SG had facilitated practitioners to reflect on their own responses in general and question how they were responding to infants, as key person two discusses:

Celebrating achievement... it's a lot of clapping and a lot of big movements, you know, and we are really celebrating that, but I have noticed that celebration now for me doesn't have to be so obvious, now it can be a very small gesture... like a smile.

Using symbolic gesturing, therefore, lessened regular exaggerated gestures and whilst deictic gestures remained valuable in communication the increased use of SG, and representational gestures created further opportunities for shared meanings (Nelson et al, 2012). The quality of signs and the reduction to a tokenistic recognition of achievement proved to be more effective in enabling practitioners to understand and support the infants' emotional wellbeing. Opportunities to enhance emotional connections were therefore occurring in the practitioners own emotional journey throughout their interactions as a result of using SG.

Practitioner three and two explored this connectivity when they spoke about the relationship becoming more expressive and congruent because of using SG. Practitioner two felt the confidence of both parties was improving and thus they were almost taking more risks in the openness of their personal feelings than had previously been evident:

Children feel they could come to me a lot more and I have got a lot more open and a lot more expressive. I was anyway, but now I am a lot more. I look a lot more open than before. I respond rather than initiate and reflect on how I am conveying messages to my group and individually. 
In verbal and SG communication, the development of reciprocal responses from the caregivers to the infants, interactions and emotional interactional behaviour of infants have been shown to be enhanced (Vallotton, 2009; Capone and McGregor, 2004; Goodwyn et al, 2000). It has the capacity to integrate infants into their cultural world of communication and Zammit and Atkinson (2016) evaluated maternal mind mindedness was evident during SG, with the infant considered a communicative partner and concluded SG aided the view of infants as autonomous individuals. This was illustrated with practitioners one evaluating the way practitioners worked together with infants in their care;

The less confident key persons will copy and model the confident practitioners. An example of this was yesterday in carpet time, one of the new apprenticeships who had been working with a more senior staff who was really conscious about body language was gesturing really beautifully about the weather today and babies were really interested in what she was doing, how she was moving. They seemed to be in the moment together and enjoying each other's company. Some even initiated their own signs to the songs rather than simply copying! It just goes to show how SG can support and develop confidence when we are doing it and demonstrating it. The apprentice was relaxed, and the babies responded to her and then the babies responding back. There was a real snowball effect... perpetuates the response

Current thinking within EYFS (2017) refers to the infant needing a key person relationship and, where possible, a one-to-one relationship where the relationship can become intimate so that consistent care is provided. As the weeks progressed SG was observed to be used a natural part of everyday communication rather than just during focused activities, as practitioner two commented:

I think when you sign you become more aware of the individual within the group and this is helpful during song time or lunch and rest. You sign to an individual and look for the responses. Previously, by just using language, it was so easy just to sort of go over the infants, giving instructions about what to do, without intending to. Now I try to use it when I can throughout the day, such as when we move room or I explain what we are doing next, such as nappy changing.

SG was therefore significant in terms of practitioners reflecting on their own behaviour and physical movement when reacting to the infants in their care. Similarly, in Vallotton's study sensitivity and responsiveness were more evident to children during interactions in which the caregiver was engaging with them using SG (2008). As a result of practitioners' initiation in using SG and empathic responsiveness it facilitated, a process of shared learning and emotional shift within the relationship with the infant was created.

\section{Conclusion}

In this study three practitioners' loved experience of engaging with SG has been explored. SG not only provided an opportunity for practitioners to interact with each infant in a sensitive way but also 


\section{References}

Abbott, L. and Moylett, H. (2003) Working with under threes responding to children's need. Berkshire: OUP.

Acredolo, L. and Goodwyn, S. (1988). Symbolic Gesturing in normal infants. Child Development, $59.450-466$.

Barnes, P. (1995) Personal, social and emotional development of children. Milton Keynes: Blackwell Publishing.

Belsky, J., Burchinal, M., McCartney, K., Vandell, D., Clarke-Stewart, K. and Owen, M. (2007) Are There Long-Term Effects of Early Child Care? Child Development. 78.(2)681-701.

Bowlby, J. (1997) Attachment. London: Pimlico. 
Braun, V. and Clarke, V. (2006). Using thematic analysis in psychology. Qualitative Research in Psychology, 3 (2), 77-101.

Brooks-Gunn, I,. Sidle-Fuligini, A,. and Berlin, L,J,. (2003) Early Child Development in the 21st Century: Profiles of current research initiatives. New York. Teachers college press.

Capone, N. C., and McGregor, K. K. (2004). Gesture development: A review for clinical and research practices. Journal of Speech, Language, and Hearing Research.47. 173-186.

Capirci, O., Iverson, J. M., Pizzuto, E., \& Volterra, V. (1996). Gestures and words during the transition to two-word speech. Journal of Child Language, 23, 645-673. 508 34(6)

Collier, J. and Collier, M. (1986) Visual anthropology: Photography as a research method. Albuquerque. University of New Mexico Press.

Daniels, M. (2004) Happy Hands: The Effect of ASL on Hearing Children's Literacy. Reading, Research, and Instruction. 44 (1) 86-100.

Dahlberg, G., Moss, P. \& Pence, A.R. (2007). Beyond quality in early childhood education and care: languages of evaluation, 2nd edn., London: Routledge.

Datler, W,. Datler, M,. and Funder, A,. (2010) Struggling against a feeling of becoming lost: A young boys painful transition to day-care. International journal of infants observation. 13 (1) 65-87.

Denzin, N. and Lincoln, Y. (2008) (ed) Handbook of qualitative research. Thousand Oaks, CA: Sage. Department for Education (DfE) (2017) The Statutory Framework for the Early Years Foundation Stage. Cheshire: DfE.

Dowling. M. (2013) Young Children's Personal Social and Emotional Development. 2nd ed. London: Sage.

Drugli, M.B., and A.M. Undheim (2011). Relationships between young children in full time day care and their caregivers: A qualitative study of parental and caregiver perceptions. Early Childhood Development and Care. 26 35-42.

Ebbeck, M., and H. Yim. 2009. Rethinking attachment: Fostering positive relationships between infants, toddlers and their primary caregivers. Early Child Development and Care 179, 7. 899-909. 
Elfer, P. (2006) Exploring children's' expressions of attachments in nursery. European Early Childhood Education. 14 (28) 1-95.

Elfer, P., Goldschmied E. and Selleck, D. (2012) Key Persons in the Early Years: Building Relationships for Quality Provision in early years settings and primary schools. Abingdon. Routledge Erben, M. (1998) Biography and Education. London. Falmer Press.

Fitzpatrick, E. M., Thibert, J., Grandpierre, V., and Johnston, J. C. (2014). How Handy are infant signs? A systematic review of the impact of gestural communication on typically developing, hearing infants under the age of 36 months. First Language. 34 (6) 486-509.

Gerdhardt, S. (2004) Why Love Matters. London. Routledge.

Goldin-Meadow, S. and Singer, M. (2003) From Children's Hands to Adults' Ears: Gesture's Role in the Learning Process. Developmental Psychology.39 (3) 509-520.

Goodwyn, S. W., and Acredolo, L. P. (1993). Symbolic gesture versus word: Is there a modality advantage for onset of symbol use? Child Development. 6. 688-701.

Goodwyn, S. W., Acredolo, L. P., and Brown, C. (2000). Impact of SGon early language development. Journal of Nonverbal Behavior, 24, 81-103.

Goouch, K. and Powell, P. (2010) Who Cares? Nursery World. 14. 22-23.

Gwyneth, D, S. (2008). The great infant signing debate. Psychologist. 21 (4) 300-303.

Harding, J. (2013) Qualitative data analysis from start to finish. London. Sage.

Hochschild, A. (2003) The managed heart. LA. University of California Press.

Holmes, J. (2001) The search for the secure base. London. Routledge.

Holmes, K. M., and Holmes, D. W. (1980). Signed and spoken language development in a hearing child of hearing parents. Sign Language Studies.28. 239-254.

Hopkins, J. (1988) Facilitating the development of intimacy between nurses and infants in day nurseries. Early Child Development and Care. (33) 99-111

Howlett, N., Kirk, E., and Pine, K. (2011). Does 'wanting the best' create more stress? The link between infant sign classes and maternal anxiety. Infant Child Development. 20 (4) 437-445. 
Iverson, J. M., Capirci, O., Longobardi, E., and Cristina Caselli, M. (1999). Gesturing in mother-child interactions. Cognitive Development.14.57-75.

Johnston, J., Durieux-Smith, A., and Bloom, K. (2005). Teaching gestural signs to infants to advance child development: A review of the evidence. First Language, 25, 235-251.

Kirk, E., Howlett, N., Pine, K. J., and Fletcher, B. C. (2013). To sign or not to sign? The impact of encouraging infants to gesture on infant language and maternal mind-mindedness. Child Development, 84, 574-590.

Kvale, S. (1996) InterViews - An Introduction qualitative research interviewing. Thousand Oaks. Sage.

Kvale, A. (2006) Dominance Through Interviews and Dialogues. Qualitative Inquiry. 12 (3) 2-22.

Lally, J. R., \& Mangione, P. (2006). The uniqueness of infancy demands a responsive approach to care. Young Children. 61. 14-19.

Liszkowski, U., Carpenter, M., Striano, T., and Tomasello, M. (2006). 12-and 18-month-olds point to provide information for others. Journal of Cognition and Development. 7.173-187.

Locke, J. L. (2007). Bimodal signaling in infancy: Motor behavior, reference, and the evolution of spoken language interaction studies. Interaction Studies. Social Behaviour and Communication in Biological and Artificial Systems, 8, 159-175.

Manning-Morton, J., and Thorp, M. (2006). Key Times: A framework for developing high quality provision for children from birth to three. Maidenhead: Open University Press.

Messinger, D. and Fogel, A. (1998) Give and Take: The development of conventional infant gestures. Merill Falmer Quarterly. 44.566-590.

Miller, L., Cable, C. and Devereux, J. (2005) Developing early years practice. London. David Fulton.

Miller, J. L., and Lossia, A. K. (2013). Prelinguistic infants' communicative system: Role of caregiver social feedback. First Language. 33. 524-544.

Mooney, C. (2010) Theories of attachment. St Paul.Redleaf Press

Mueller, V and Sepulveda, A (2014) Parental Perception of a infant sign workshop on stress and parent-child interaction. Early child development and care. 184 (3) 450-468 
Namy, L. I., Acredolo, A., and Goodwyn, G. (2000). Verbal labels and gestural routines in parental communication with young children. Journal of Nonverbal Behavior, 24. 63-79.

Nelson, L. H., White, K. R., and Grewe, J. (2012). Evidence for website claims about the benefits of teaching sign language to infants and toddlers with normal hearing. Infant and Child Development, 21 (5) $474-502$.

Noland, C. (2006) Autophotography as research practice: identity and self esteem research. Journal of Research Practice. 2. 1-19

Olson, J., \& Masur, E. F. (2013). Mothers respond differently to infants' gestural versus nongestural communicative bids. First Language, 33, 372-387.

Ochs, E. and Schieffelin, B. (1984) Language acquisition and socialization: Three developmental stories and their implications. Online at www.stanford.edu/Ochs_Schieffelin_1989 reading_notes_Schnoe (accessed 01/2016)

Meil, D. and Dallos, R. (2005) Social interaction and personal relationships, Milton Keynes: OUP

Pizer, G. (2004) Infant signing as language socialization: the use of visual gestural signs with hearing infants. Proceedings of the eleventh annual symposium about language and society. Texas Linguistic Forum. 47.165-171.

Pizer, G., Walters, K. and Meier, P. (2007) Bringing up infant with infant signs: Language ideologies and socialisations in hearing families. Sign Language Studies. 7(4)143-159.

Powell, S. (2009) Not allowed to kiss the infants: complexities and contradictions in infant room policies and practice. Canterbury University Article: European Meeting of OMEP, University of Chester.

Pugh, G. and Duffy, B. (2013) Contemporary Issues in the early years. London. Sage.

Read, V. (2010) Developing attachments in early years settings. London. Routledge.

Rowe, M. and Goldin-Meadow S. (2008) Early gesture selectively predicts later language learning. Developmental Science, 12(1)182-187.

Smith, P., Cowie, H. and Blades, M. (2005) Understanding children's development. London: Blackwell Publishing. 
Taggart, G. (2011) Don't we care? The ethics and emotional labour of early years professionalism. Early Years, 31 (1) 85-95.27.

Trevarthen, C. (1998). The concept and foundations of infant inter-subjectivity, cited in S. Bråten (Ed.), Intersubjective communication and emotion in early ontogeny. Cambridge University Press.

Trevarthen, C. (2001) Intrinsic motives for companionship in understanding; their origin development and their significance for mental health. Infant Mental Health Journal, 22, 95-131.

Tomasello, M., and Farrar, M. J. (1986). Joint attention and early language. Child Development, 57, $1454-1463$.

Vallotton, C. (2005) Effects of symbolic gestures as a caregiving tool: Children's social and language development and mothers' perceptions and behaviour. Dissertation Abstract International, 65 (9) 487.

Vallotton, C. (2008a) Signs of emotion: What can preverbal children "say" about internal states? Infant Mental Health Journal, 29, 234-258.

Vallotton, C. and Ayoub, C. (2009) Symbols build communication and thought: The role of gestures and words in the development of engagement skills and social-emotional concepts during toddlerhood. Social Development, 19. 601-626.

Vallotton, C. D. (2012). Infant signs as intervention? Promoting symbolic gestures for preverbal children in low income families supports responsive parent-child relationships. Early Childhood Research Quarterly.27.401-415.

Vallotton, C. D., Harewood, T., Karsten, A., and Decker, K. B. (2014). Infant signs reveal infant minds to early childhood educators in L. Harrison, \& J. Sumsion (Eds.), The lived spaces of infant and toddler education and care settings (pp. 161-172). New York, NY. Springer.

Vallotton, C, Decker, K,B., Kwon, A., Wang, W., and Chang, T. (2017) Quantity and Quality of Gestural Input: Caregivers' Sensitivity Predicts Caregiver-Infant. Bidirectional Communication Through Gestures. Infancy, 22(1), 56-77, 2017

Yin, R. (2009) Case Study Research. London. Sage.

Zammit, M and Atkinson, S (2016) The relations between infant signing child vocabulary and maternal mind mindedness. Early Child development and care. 1-9. 
